\title{
Multinomial Logistic Regression Model to Identify the Factors Associated with Academic Performance of Hearing Impaired Students of Some Selected Districts of Nepal
}

Tara Devi Rijal $^{1 *}$ and Gauri Shrestha ${ }^{2}$

Submitted: 19 July 2019; Accepted: 15 August 2019

Published online: 16 September 2019

DOI: https://doi.org// 0.3 I 26/njs.v3i0.25577

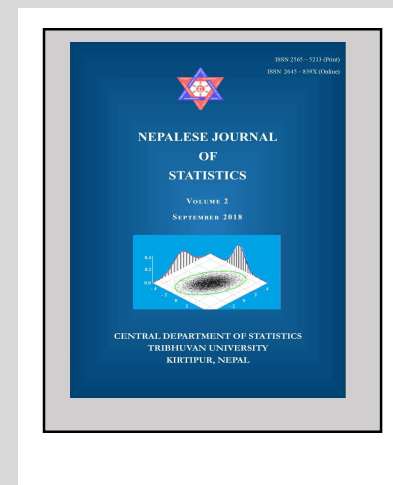

\section{ABSTRACT}

Background: Education for hearing impaired $(\mathrm{HI})$ students is always challenging for schools, teachers, parents and even for students themselves. For their education, government has established special schools and included them in mainstream school with hearing peers also called integrated school. Although all these efforts for their education, their academic performance is affected by different factors.

Objective: This study is focused to assess factors which affects the academic performance of $\mathrm{HI}$ students of Jhapa, Morang and Sunsari districts.

Materials and Methods: This study is a cross-sectional study and based on primary data collected through structured questionnaire. Academic Performance is categorized as Below Average, Average and Good. A sample of $238 \mathrm{HI}$ students from eleven schools of three districts were selected using two stage stratified random sampling methods. Sixty teachers were also chosen for assessing some variables. Data were analyzed using descriptive and inferential statistical methods. To determine the significant factors influencing the academic performance of $\mathrm{Hl}$ students, Multinomial Logistic Regression (MNLR) model was used.

Results: From the fitted MNLR model, variables like attendance [Odds Ratio $(O R)=0.95 \mathrm{I}$ ], type of school $(O R=27.39)$, level of study $(O R=4.55 \mathrm{I})$, additional handicapping condition $(O R=5.202)$, communication capacity of students $(O R=9.477)$ and instructional material $(O R=3.028)$ are found to be significant in the model Below Average versus Average level of academic performance of $\mathrm{HI}$ students. Similarly, the variables like type of school ( $O R=7.875$ and 9.572), level of study ( $O R=$ 0.556), purpose of parents' visit $(O R=0.410)$ and instructional material $(O R=0.304)$ are found to be significant in the model Good versus Average level of Academic performance of HI students.

Conclusion: The results of the study illustrates that several factors are associated with academic performance of $\mathrm{HI}$ students. Concerned authorities are suggested to provide suitable 
infrastructure, $\mathrm{HI}$ students friendly curriculum, special training to teacher and awareness to family, society and hearing peers to improve the academic performance of $\mathrm{HI}$ students.

Keywords: Academic performance, chi-square test, hearing impaired students, multinomial logistic regression, odds ratio, two- stage stratified random sampling.

Address correspondence to the author: Orchid International College, Tribhuvan University, Gaushala, Kathmandu, Nepal. E-mail: metararijal@gmail.com ${ }^{*}$ (Corresponding author); Central Department of Statistics, Tribhuvan University, Kirtipur, Kathmandu, Nepal. E-mail: gaurishrestha@yahoo.com ${ }^{2}$

\section{INTRODUCTION}

The hearing loss is defined as a person who is not able to hear or someone with hearing threshold of $25 \mathrm{~dB}$ or more in both ears. It may be mild, moderate, severe or profound. One or both ears can be affected and leads to difficulty in hearing conversational speech or loud sound. People with hearing loss ranging from mild to severe are also referred as Hard of hearing. People with profound hearing loss, which implies very little or no hearing is referred as Deaf (WHO, 2017). Education to $\mathrm{HI}$ person involves individually planed, systematically monitored teaching methods, adaptation of suitable materials, accessible setting. Although all these efforts, many factors play role in the academic achievement of Deaf and Hard of Hearing (DHH) students. (Marschark, Shaver, Nagle, \& Newman, 2015). Importance of education is widely accepted in this era. The people with disability are being able to adapt in the society by means of education. But education for people with disability requires different methods and facilities than the normal students. Their academic performance tells how well they are being successful in understanding the studies and doing tasks. To measure the academic performance of students, the result of previous year or particular subject is used (Hijazi \& Naqvi, 2006). Grades and GPA are also used to measure the academic success (York, Gibson \& Rankin, 20I5).

Countries all over the world committed to inclusive education. Inclusive education is a process of addressing and responding to diversity of needs of all learners on the classrooms, in the school and on the society and thereby reducing exclusion within and from education no matter what causes for exclusion could be (UNESCO, 2015). The provision of education to person with disability in Nepal can be traced back to 202I BS when Esabel Grant, a blind America woman, took initiation and started a class for 9 Nepalese blind students in laboratory school, Kirtipur. After that a school for HI children was established in 2023 BS in Balmandir, Naxal, Kathmandu. Similarly, special school for blind and intellectually disabled in 2026 BS and for intellectually disabled in 2038 BS were established. This number now reached to 380 resource classes, 32 special schools and 22 integrated schools. Now, in these schools total 74,829 students are enrolled from fundamental to secondary level (Government of Nepal, 2073 BS).

42 www.tucds.edu.np ISSN: 2565-52 I 3 (Print); 2465-839X (Online) 
To promote equal access to education to all children including children with disability, the government of Nepal has put forwards lots of efforts. Nepal has committed to international declarations, protocols and conventions related to education to all and took initiations for inclusive education. Constitution of Nepal has also guaranteed the free education to hearing and speech impaired citizen with use of sign language as a fundamental right (Government of Nepal, 2015). Eight Amendment to education act 2073 BS also focused on special education to people with disability. It allows any school to run special class for child with disability in school (Government of Nepal, 2016). Effort of government is not confined to legislation provision only, focus to establish some school for children with disability also. Currently, there are three main categories of school available for children with special needs (Thapalia, 2016) viz. Special schools, Resource class Integrated School. And, till now there are 13 special schools for students with hearing impairment and 127 integrated school including resource classes (Government of Nepal, 2017). Some more examples that aim to promote the education of children with disability are free education up to higher education, scholarship and residential facility at the school level, free textbooks including the Braille materials for the blind students, priority in recruiting people who have disability in teaching, teacher training and management of resource classes to ensure transfer to regular classes (Government of Nepal, 2014). Despite the efforts and achievements of Education For All and the Millennium Development Goals, children with disabilities remain one of the main groups that continue to be excluded from education around the world (UNESCO, 2015). Among students with disability in $\mathrm{Nepal}$, a number of $\mathrm{Hl}$ students studying in primary level is 7274 . These numbers in lower secondary, secondary and higher secondary level goes on descending order as 2382, 895 and 174 respectively (Government of Nepal, $2073 \mathrm{BS}$ ). This shows that the rate of drop out of students with hearing impairment is high on going higher classes.

Although promising development in the education of hearing and speech impaired student their achievements continue to lag behind than that of hearing peer and many of them do not acquire the knowledge and skill to reach their full potential (Marsdhark et al., 20I5). Researchers suggest several reasons for this troubling and long standing under achievement. Marschark et al. (2015) suggested characteristics of students, characteristics of their family environments and experiences inside and outside classrooms are some of those factors. The study carried out by Dynamic Institute of Research and Development, Kathmandu focused that inadequate training to teacher, lack of resources for trained teachers, no incentive to motivate teacher, unfriendly infrastructure of the school, inadequate financial resources, school/teacher failing to address individual differences of students, lack of disability specific supporting materials like brail book, audio recording, pictures, equipment etc.; least support from the part of the parents and the family members; lack of disability specific contents in the curricula/textbook and assessment system are some factors that hinder the academic performance of students with disability in Nepal (Government of Nepal, 2014). Powers (2003) mentioned that great numbers of factors are involved in influencing the academic achievement of deaf students and interrelations among the factors are complicated. He summarized the factors affecting the academic achievement of students into three categories. First, Students factors second, family factors and finally, school factors. 
Human Right Watch (20II) highlighted the difficulties that the children with disability are facing in obtaining a quality education in Nepal. Some of them are experiencing abuse and neglect at home and their communities. It makes them hard to gain access to schooling. These barriers result in low attendance and high dropout rates for children with disability compared to their non-disabled peers. The study by Mwanyuma (2016) found that strong negative correlation between negative perception from society, rigid curriculum, simplified language of instruction, lack of learning resources with academic performance of Deaf learners.

Different researchers used different research methods in above studies. Marschark et al. (2015) used four step multilevel regression analysis with the objective of examination of relative contribution of four clusters (individual and household characteristics, disability identifications, hearing and communications and educational experience) to the explained variance. Power (2003) applied multiple linear regression to provide an estimate of the relative importance of different independent variables in producing changes in the dependent variable (academic outcomes). To analyze the factors influencing the academic achievement of deaf learners descriptive statistic were used (Mwanyuma, 2016). In this research the influence of different factors on academic performance of $\mathrm{HI}$ students studying in special, integrated and normal school with recourse class are examined.

\section{MATERIALS AND METHODS}

\section{Data and study area}

The study is based on the primary data collected by the researcher. The study area is Jhapa, Morang and Sunsari districts of province I. There are 13 government aid special and integrated schools including resource classes for $\mathrm{HI}$ students in those districts. The study population is defined as the total number of $\mathrm{HI}$ students who were studying in government aid special and integrated school including resource classes of Jhapa, Morang and Sunsari. Information about population is gathered from Jilla Lekha Jokha Kendra of Jhapa, Morang and Sunsari districts. Jilla Lekha Jokha Kendra keeps record of students with disabilities studying within that district. Total population are '453 students studying in 13 such schools in those study area during academic year 2074 BS. For this study two schools having students less than 10 has been excluded. So that, population for this study become 44I after excluding I 2 students from those two schools. 238 sample was taken and it was determined by using the formula (Cochran, 1997).

The sample was collected using two stage Stratified Random Sampling with Proportional Allocation method. In the first stage, the overall population (44I HI students of Jhapa, Morang and Sunsari districts) were divided into three strata on the basis of type of school viz. Special School, Integrated School and Resource Class. Next, each school type was divided into three strata on the basis of level of study viz. Primary level, Lower Secondary level and Secondary level. Then the samples were drawn from each strata using simple random sampling without replacement method with the help of random number table. A study protocol was approved by the Research Committee

44 www.tucds.edu.np ISSN: 2565-52 I 3 (Print); 2465-839X (Online)


of Central Department of Statistics, TU, Kathmandu. The data was collected using structured questionnaire developed by the researchers for this study. Respondents were enumerated using face to face interview by researchers. The translation help was taken from the hearing teachers of the same school who were expert in sign language. Some more information which were unable to get from students were collected from the teachers, each from one class. For this purpose total 60 teachers, who were present in the class room at the time of data collection, were involved.

\section{Study variables}

Academic performance is dependent variable in this study. Score (GPA or percentages) obtained by students in final exam of academic year 2074 BS performed by school is taken as academic performance which is further categorized into 3 groups as (i) below average/insufficient (below 45 percent (ii) Average (45-59 percent) and (iii) good (above 60 percent). Different variables gender, cause of disability, place of stay, parents visit to students' residence, purpose of parents visit to school, parent's encouragement to study, presence of $\mathrm{HI}$ family member, perception of society and hearing peer on deafness, teasing by hearing peers, additional handicapping condition, types of school, level of study, use of sign language by teacher, communication capacity of students, instructional material, assistance by instructional material, availability of school facility, content coverage and reason of not covering content are taken as independent variables by categorizing them in to Demographic, Socio-cultural, Student's, Communication and Curriculum factors.

\section{Statistical methods}

To meet the objectives of the study, uni-variate and bivariate analysis are used in this study. To determine the significant factors influencing academic performance of $\mathrm{HI}$ students, which is ordinal in nature, ordinal logistic regression model was tried first but assumption of test of parallel lines in ordinal logistic regression model was violated. Then multinomial logistic regression (MNLR) model was used after verification of the validity of fitted model by applying different model adequacy test. Let us assume that the categories of the outcome variable (i.e. Academic performance), $Y$, is coded as I, 2 and 3 for Below Average, Average and Good respectively. We contrast category I versus 2 and 3 versus 2 . The missing contrast between categories I and 3 can easily be obtained in terms of the other two. Since

$$
\ln \frac{\pi_{i 1}}{\pi_{i 3}}=\ln \frac{\pi_{i 1}}{\pi_{i 2}}-\ln \frac{\pi_{13}}{\pi_{i 2}}
$$

Let, $Y_{i j}=\left\{\begin{array}{cc}1, \text { if theindividual fall incategory } j \\ 0, & \text { otherwise. }\end{array}\right.$

where, $\mathrm{j}=\mathrm{I}, 2,3$

Let, $\quad \pi_{i j}=\operatorname{Pr}\left(Y_{i j} j \mid X\right)$ denote the probability that $\mathrm{Y}_{\mathrm{ij}}=\mathrm{j}$

Assuming that the response categories are mutually exclusive then we can write, $\sum_{j=1}^{3} \pi_{i j}=1$ 
We now consider model for $\Pi_{\mathrm{ij}}$, in particular, consider model where their probabilities depend on a vector $X_{k}$ of covariates associated with the $i^{\text {th }}$ individuals.

$\ln \frac{\pi_{i j}}{\pi_{i 1}}=\ln \frac{P\left(Y_{i j}=j \mid X\right)}{P\left(Y_{i 1}=1 \mid X\right)}=\alpha_{j}+\sum_{k=1}^{g} \beta_{j k} X_{k} \quad$ where $\mathrm{j}=2,3$, and $\alpha_{\mathrm{j}}$, is a constant. $\beta_{\mathrm{jk}}$, is the regression coefficient for $j=2,3$ and $X_{k}(k=1,2, \ldots, g)$ are explanatory variables. The MNLR model may also be written in terms of probability $\Pi_{\mathrm{ij}}$,

$$
\pi_{i j}=\frac{e^{\alpha_{j}+\sum_{k=1}^{g} \beta_{j k} X_{k}}}{1+e^{\alpha_{j}+\sum_{k=1}^{g} \beta_{j k} X_{k}}}
$$

Estimation of the parameters of this MNLR model is done by iteratively reweighted least square, which is identical to the logarithm of fisher scoring or Newton-Raphsons and lead to maximum likelihood estimates (McCullagh \& Nelder, 1989).

\section{RESULTS}

This study shows that about 40.3 percent of students of this study were able to score Good marks, about 34.5 percent scored Average and about 25.2 percent scored below Average (Table I).

Table I. Distribution of the dependent variable.

\begin{tabular}{lll}
\hline Academic Performance & Frequency $(\mathrm{n})$ & Percentage $(\%)$ \\
\hline Below Average & 60 & 25.2 \\
\hline Average & 82 & 34.5 \\
\hline Good & 96 & 40.3 \\
\hline Total & 238 & 100.0 \\
\hline
\end{tabular}

Distribution of Demographic, Socio- cultural, students', Communication and Curriculum factors under study in this research are presented in Table 2.

Table 2. Selected background characteristics of HI students under study $(n=238)$.

\begin{tabular}{cllcc}
\hline Factors & Variables & Categories & $\mathbf{n}$ & $\%$ \\
\hline \multirow{5}{*}{ Demographic } & Red & $\mathrm{I}$ & 0.4 \\
& \multirow{4}{*}{ Disability Card Type } & Blue & 227 & 95.4 \\
& & Yellow & 5 & 2.1 \\
\cline { 3 - 5 } & \multirow{2}{*}{ Gender } & Without Card & 5 & 2.1 \\
\cline { 3 - 5 } & & Male & 124 & 52.1 \\
\cline { 3 - 5 } & \multirow{2}{*}{ Cause of Disability } & Female & 114 & 47.9 \\
\cline { 3 - 5 } & \multirow{3}{*}{ Socio-cultural } & Congenital & 216 & 90.8 \\
\cline { 3 - 5 } & \multirow{2}{*}{ Stay } & Acquired & 22 & 9.2 \\
\cline { 3 - 5 } & & Hostel & 190 & 79.8 \\
\hline
\end{tabular}




\begin{tabular}{llcc}
\hline & & \multicolumn{3}{c}{ contd... } \\
\hline \multirow{3}{*}{ Parents visit to student's residence } & No visit & 55 & 26.19 \\
\cline { 2 - 4 } & Sometimes & 122 & 58.09 \\
\cline { 2 - 4 } & Most often & 33 & 15.72 \\
\hline
\end{tabular}

Purpose of parents visit to school

Child related

Administrative purpose only $\quad 161 \quad 67.6$

Presence of Hearing impaired family
member

Teasing by hearing peers

Hearing peers' perception on deafness

Ho

Society's perception on deafness

\begin{tabular}{|c|c|c|c|c|}
\hline & & & \\
\hline & & Positive & 47 & 19.8 \\
\hline \multirow{8}{*}{ Students } & \multirow{2}{*}{ Additional Handicapping condition } & No & 219 & 92.0 \\
\hline & & $\overline{\text { Yes }}$ & 19 & 8.0 \\
\hline & \multirow{3}{*}{ Type of School } & Special school & 103 & 43.3 \\
\hline & & Integrated school & 52 & 21.8 \\
\hline & & Resource class & 83 & 34.9 \\
\hline & \multirow{3}{*}{ Level of study } & Primary & 119 & 50.0 \\
\hline & & Lower secondary & 75 & 31.5 \\
\hline & & Secondary & 44 & 18.5 \\
\hline \multirow{6}{*}{ Communication } & \multirow{3}{*}{ Use of sign language by teacher } & None & 42 & 17.6 \\
\hline & & Some & 73 & 30.7 \\
\hline & & $\overline{\text { All }}$ & 123 & 51.7 \\
\hline & \multirow{3}{*}{ Communication capacity of students } & Some difficulty & 69 & 29.8 \\
\hline & & Easily & 132 & 55.5 \\
\hline & & Quite easily & 37 & 15.5 \\
\hline \multirow{7}{*}{ Curriculum } & \multirow{3}{*}{$\begin{array}{l}\text { Instructional } \\
\text { material }\end{array}$} & $\begin{array}{l}\text { Charts/graphs } \\
\text { only }\end{array}$ & 67 & 28.2 \\
\hline & & $\begin{array}{l}\text { Charts/graphs and } \\
\text { teachers made }\end{array}$ & 80 & 33.6 \\
\hline & & Board only & 91 & 38.2 \\
\hline & \multirow{2}{*}{$\begin{array}{l}\text { Assistance by instructional } \\
\text { material }\end{array}$} & Yes & 147 & 61.8 \\
\hline & & $\begin{array}{l}\text { Yes! if they have } \\
\text { used }\end{array}$ & 91 & 38.2 \\
\hline & \multirow{2}{*}{$\begin{array}{l}\text { Content coverage } \\
\text { (collected from teachers) }\end{array}$} & No & 53 & 88.3 \\
\hline & & $\overline{\text { Yes }}$ & 7 & 11.7 \\
\hline
\end{tabular}

Out of 238 students, the majority of the respondents $95 \%$ were found bearing Blue color disability card, $52 \%$ were male, $92 \%$ had disability by birth, $8 \%$ were having rental room for accommodation, $26 \%$ students' parents did not visit to students' residence, only $32 \%$ parents had 
visited school to discuss about children education, only $18 \%$ had hearing impaired family member, $43 \%$ children had faced teasing from hearing peers, $70 \%$ thought hearing peers and society have neutral thinking towards them, $92 \%$ had no any additional handicapping conditions, $43 \%$ were from special school, $22 \%$ were from integrated school, $35 \%$ were from resource class, $18 \%$ students said no any teacher uses sign language at all to teach, only I5\% students were fluent in sign language, $38 \%$ were taught only via board and they thought it would have been better if they were taught using enough instructional materials. $88 \%$ of teachers couldn't cover all the course content within one academic year (Table 2) so that they were asked multiple response question to explore the reasons behind it. $98 \%$ mentioned that curriculum is not suitable for $\mathrm{HI}$ students, $67 \%$ mentioned due to insufficient instructional material, $65 \%$ mentioned that they need more time to explain, $65 \%$ mentioned due to lack of sign for word or concept and $36 \%$ mentioned due to incompetence in sign language. And students were also asked about school facility by multiple response questions. $75 \%$ students were getting facility of well-furnished classroom, $63 \%$ were in separate room for their respective class and among them only $52 \%$ got opportunity to study with subject teacher for their class. Unfortunately 13\% HI students were taught in mixed class without any above mentioned facilities.

Table 3. Bivariate analysis.

\begin{tabular}{|c|c|c|c|}
\hline Factors & Variables & $\chi^{2}$-value & (p-value) \\
\hline \multirow{6}{*}{ Socio-cultural } & $\begin{array}{l}\text { Stay } \\
\text { Purpose of parents visit to } \\
\text { school }\end{array}$ & $\begin{array}{l}4.948 \\
15.809\end{array}$ & $\begin{array}{l}0.293 \\
(<0.001)\end{array}$ \\
\hline & Teasing by hearing peers & 6.469 & $(0.039)$ \\
\hline & $\begin{array}{l}\text { Hearing peers' perception on } \\
\text { deafness }\end{array}$ & 13.004 & $(0.011)$ \\
\hline & Society's perception on & & \\
\hline & deafness & 12.240 & $(0.016)$ \\
\hline & $\begin{array}{l}\text { Presence of hearing impaired } \\
\text { family member }\end{array}$ & 0.106 & 0.948 \\
\hline \multirow{3}{*}{ Students } & $\begin{array}{l}\text { Additional Handicapping } \\
\text { condition }\end{array}$ & 11.730 & $(0.003)$ \\
\hline & Type of School & 35.269 & $(<0.00 \mathrm{I})$ \\
\hline & Level of study & 14.617 & $(0.006)$ \\
\hline \multirow[b]{2}{*}{ Communication } & Use of sign language by teacher & 38.048 & $(<0.00 \mathrm{I})$ \\
\hline & $\begin{array}{l}\text { Communication capacity of } \\
\text { students }\end{array}$ & 15.627 & $(0.004)$ \\
\hline Curriculum & Instructional material & 58.765 & $(<0.00 \mathrm{I})$ \\
\hline
\end{tabular}


The $\chi^{2}$ - square test of academic performance by some variables (Table 3 ) reveals that these variables have statistically significant impact on academic performance of $\mathrm{HI}$ students and were included in logistic regression analysis. Non- significant predictors were removed from the final fitted model. The ordinal logistic regression model had been tried to fit by taking the Academic Performance having three categories (Below Average, Average and Good) as dependent variable and above listed significant variables as predictors. The fundamental assumption of the ordinal logistic regression model is the assumption of proportional odds which is tested by test of parallel lines. In this research, this test was seen to be significant which indicates that the location parameters (slope coefficient) are same across response categories. So alternative model needs to be considered for exploring the factors associated with academic performance of $\mathrm{HI}$ students. Due to violation of assumption of parallel lines test, an alternative model, the MNLR model was used.

Table 4 represents the estimates of multinomial logistic regression coefficient, $\mathrm{p}$-value and odds ratio for each category. From the fitted MNLR, the variables like attendance $(O R=0.95 \mathrm{I}, \mathrm{p}$ value $<0.00 \mathrm{I})$, type of school 'special school' $(O R=29.37$, $p$-values $<0.00 \mathrm{I})$, level of study 'Lower Secondary' $(O R=4.55 \mathrm{I}, \mathrm{p}$-value $<0.05)$, additional handicapping condition $(O R=5.202$, $\mathrm{p}$-value $<$ $0.05)$, communication capacity of students' some difficulty' $(O R=9.477, p$-value $<0.05)$ and instructional material 'nothing only board' $(O R=3.028$, $p$-value $<0.05)$ are seen to be significant to the model Below Average versus Average level of academic performance of $\mathrm{HI}$ students. Similarly, the variables like type of schools 'resource class' and 'special school' (OR=7.875 and 9.572, $p$-value $<0.05)$, level of study 'secondary level' $(O R=0.556, p$-value $<0.05)$, purpose of parents' visit $(O R=0.410, p$-value $<0.05)$ and instructional material $(O R=0.304, p$-value $<0.00 \mathrm{I})$ are found to be significant to the model Good versus Average level of academic performance of $\mathrm{HI}$ students. The factor type of school (integrated school) and instructional material are seen to be significant in both cases.

The odds ratio for attendance is seen to be 0.915 for the model Below Average versus Average, it reveals that the odds of getting below average grade relative to average grade to the students who attended one day more is 8 percent less as compared to those who attended one day less. It means that the students who come school regular has less chance of obtaining below average grade. But it didn't show the significant effect for the model Good versus Average level of academic performance. The odds ratio of special school as compared to integrated school for the model Below Average versus Average is 29.37 which indicates that the students of special school are 29.37 times more likely to get below average grade relative to Average grade as compared to the students of integrated school. However, in case of Good versus Average model the odds ratio of special school as compared to integrated school is 9.572 which indicates that the students of special school are 9.575 times more likely to get good grade relative to average grade as compared to the students of integrated school. Similarly, the odds ratio of resource class as compared to integrated school is 7.875 which indicates that the students of resource class are 7.875 times more likely to get good grade relative to average grade as compared to the students of integrated school. 
But it didn't show the significant effect for the model Below Average versus Average level of academic performance.

Table 4. Final fitted model for explaining the academic performance of $\mathrm{HI}$ students.

\begin{tabular}{|c|c|c|c|c|c|c|c|c|}
\hline \multirow[t]{3}{*}{ Variable } & \multicolumn{4}{|c|}{ Below Average versus Average } & \multicolumn{4}{|c|}{ Good versus Average } \\
\hline & \multirow{2}{*}{$\begin{array}{l}\text { Estimated } \\
\text { coefficient } \\
\text { ( B ) }\end{array}$} & \multirow{2}{*}{$\begin{array}{l}\text { Odds } \\
\text { Ratio } \\
\left(\mathrm{e}^{6}\right)\end{array}$} & \multicolumn{2}{|c|}{$\begin{array}{l}95 \% \text { confidence } \\
\text { interval for odds } \\
\text { Ratio }\end{array}$} & \multirow{2}{*}{$\begin{array}{l}\text { Estimated } \\
\text { coefficient } \\
(B)\end{array}$} & \multirow{2}{*}{$\begin{array}{l}\text { Odds } \\
\text { Ratio } \\
\left(\mathrm{e}^{6}\right)\end{array}$} & \multicolumn{2}{|c|}{$\begin{array}{l}95 \% \text { confidence } \\
\text { interval for odds } \\
\text { Ratio }\end{array}$} \\
\hline & & & $\begin{array}{l}\text { Lower } \\
\text { bound }\end{array}$ & $\begin{array}{l}\text { Upper } \\
\text { bound }\end{array}$ & & & $\begin{array}{l}\text { Lower } \\
\text { bound }\end{array}$ & $\begin{array}{l}\text { Upper } \\
\text { bound }\end{array}$ \\
\hline Intercept & $3.293^{*}$ & & & & $0.276^{*}$ & & & \\
\hline Attendance & $-0.089^{* *}$ & 0.915 & 0.871 & 0.961 & 0.010 & 1.010 & 0.962 & 1.061 \\
\hline \multicolumn{9}{|l|}{ Integrated school ${ }^{\circledR}$} \\
\hline Resource class & 0.665 & 1.945 & 0.518 & 7.302 & $2.064^{*}$ & 7.875 & 1.903 & 32.589 \\
\hline Special School & $3.380^{* *}$ & 29.37 & 6.669 & 129.36 & $2.254^{*}$ & 9.572 & 2.281 & 40.177 \\
\hline \multicolumn{9}{|l|}{ Level of Study } \\
\hline \multicolumn{9}{|l|}{ Primary level ${ }^{\circledR}$} \\
\hline Secondary Level & 0.380 & $\mathrm{I} .463$ & 0.343 & 6.244 & $-0.587^{*}$ & 0.556 & 0.141 & 0.967 \\
\hline Lower Secondary & $1.515^{*}$ & 4.551 & 1.425 & $|4.53|$ & 0.558 & 1.748 & 0.531 & 5.746 \\
\hline \multicolumn{9}{|l|}{$\mathrm{No}{ }^{\circledR}$} \\
\hline Yes & $1.649^{*}$ & 5.202 & 1.225 & 22.096 & 1.186 & 3.275 & 0.607 & 17.664 \\
\hline \multicolumn{9}{|c|}{ Purpose of parents' visit } \\
\hline \multicolumn{9}{|c|}{ Discuss with the teacher on the matter related to child ${ }^{\circledR}$} \\
\hline $\begin{array}{l}\text { Administrative } \\
\text { purpose only }\end{array}$ & -0.434 & 0.648 & 0.237 & 1.770 & $-0.892^{*}$ & 0.410 & 0.181 & 0.927 \\
\hline \multicolumn{9}{|l|}{ Quite easily ${ }^{\circledR}$} \\
\hline Some difficulty & $2.249^{*}$ & 9.477 & 1.598 & 56.202 & -1.504 & 0.222 & 0.047 & 1.051 \\
\hline Easily & 0.344 & $1.41 \mathrm{I}$ & 0.325 & 6.117 & -1.215 & 0.269 & 0.070 & 1.033 \\
\hline \multicolumn{9}{|c|}{ charts/graphs and teacher's made resource ${ }^{\circledR}$} \\
\hline Charts/Graphs & 0.499 & $\mathrm{I} .647$ & 0.411 & 6.605 & $-2.75 \mathrm{I}$ & 0.064 & 0.018 & 0.223 \\
\hline Nothing & $1.108^{*}$ & 3.028 & 1.660 & 13.902 & $-1.192^{* *}$ & 0.304 & 0.077 & 1.192 \\
\hline
\end{tabular}

(R) denotes reference category, ${ }^{* *}=\mathrm{p}$ - value $<0.00 \mathrm{I}, *=\mathrm{p}-$ value $<0.05$. 
On the other hand, secondary level didn't show the significant effect for the model Below Average versus Average. However, it has significant effect on the model Good versus Average level of academic performance. The odds ratio of secondary level students as compared to primary level students is 0.556 it reveals that the students of Secondary level have 45 percent less chance of getting Good grades relative to the Average grades as compared to the students of primary level. Similarly, the odds ratio of lower secondary level students as compared to primary level students is $4.55 \mathrm{I}$ it reveals that the students of lower secondary level are $4.55 \mathrm{I}$ times more likely to get Below Average grades relative to Average grades as compared to the students of primary level. But it didn't show the significant effect for the model Good versus Average level of academic performance.

Similarly, the odds ratio of Additional handicapping condition as compared to no other handicapping condition is 5.202 which indicates that the students having additional handicapping condition are 5.202 times more likely to get Below Average grade relative to Average grade as compared to the students who have not any other handicapping condition. But it didn't show the significant effect for the model Good versus Average level of academic performance. Next, the odds ratio of students having poor communication capacity as compared to the students who can communication very easily is 9.477 which indicates that the students having poor communication capacity are 9.477 times more likely to get Below Average grades relative to the Average grade as compared to the students who can communicates very easily. But it didn't show the significant effect for the model Good versus Average level of academic performance.

The odds ratio of instructional material (only board) as compared to the charts/graphs and teacher made resources is 3.028 for the model below average versus average, which indicates that the students who did not get the opportunity to study with instructional material are 3.028 times more likely to get Below Average grade relative to the Average grade as compared to the students who got the opportunity to study with enough instructional material. Similarly, the odds ratio of instructional material (only board) as compared to the charts/graphs and teacher made resources is 0.304 for the model Good versus Average, which indicates that the students who did not get the opportunity to study with instructional materials have 70 percent less chance of getting good grades relative to average grades as compared to students who got opportunity to study with enough instructional materials.

\section{Model adequacy test}

The likelihood ratio test for the overall significance of all coefficients for the predictor as well as significance of single predictor in the model is performed. The likelihood value and final -2 Log Likelihood value are 485.333 and 339.286 , respectively. And p-value $<0.00$ I, which shows that at least one and perhaps most of the coefficient are different from zero and indicates that whole the predictors have significant contribution to predict the outcome variable. Here the chi-square test for the model is significant showing the acceptable fitting of the MNLR model. To see the overall significance of predictors in the model likelihood ratio test is done and $\mathrm{p}$ - value $<0.00 \mathrm{I}$, indicates 
that whole the predictors have significant contribution to predict the outcome variable. Hence, significant chi- square is showing the acceptable fitting of the MNLR model. A measure to assess the utility of MNLR model is the classification Accuracy, the benchmarks that will used to characterize a MNLR model as useful is a 25 percent improvement over the rate of accuracy achievable by chance alone. And in this study, the proportional by the chance accuracy criteria is $43.12 \%$ and the classification accuracy rate is $61.8 \%$ which is greater than chance accuracy. Hence, the classification accuracy is satisfied. The overall goodness of fit of the estimated model is judged by deviance and Pearson's $\chi^{2}$-test, non-significant Pearson's and deviance chi-square statistic with $\mathrm{p}$-value 0.886 and 0.986 , respectively suggest that the estimated model fit is well to the MNLR model. To measure the proportion of variation in the academic performance of $\mathrm{HI}$ students that can be explained by the predictors in the model, pseudo $R^{2}$ are calculated. Here, Negelkerke $R^{2}$ was found to be 0.518 , which indicates that $52 \%$ variation in the categories of academic performance is explained by explanatory variables.

\section{DISCUSSION}

This study was conducted to explore the factor associated with academic performance of $\mathrm{HI}$ students. On the basis of result of estimates of MNLR model, attendance, types of schools, level of study, additional handicapping conditions, purpose of parents' visit to school, communication capacity of students and Instructional material used have been found most influential variables on academic performance of $\mathrm{HI}$ students. Academic performance of students in special school and resource class is relatively better than the students of integrated school. This indicates that, placement in a special setting for $\mathrm{HI}$ students is observed more likely to be the academic progress rather than mixed with them in a regular class in integrated schools. In contrast to our result, the study by Holt (1993) on the data of special achievement test of deaf and hard of hearing students of United States conducted by Center for Assessment and Demographic Studies reported that the highest median scaled scores are: 643 (with grade equivalents of 5.7) for integrated school programs, 609 (with grade equivalents of 3.8) for special school programs and 584 (with grade equivalents of 2.8) for non-integrated local school program, indicates that median standard achievement test reading comprehension scores were higher for $\mathrm{HI}$ students in general education classrooms than those in separate classrooms.

Use of instructional material is positively correlated with academic performance of $\mathrm{HI}$ students. Instructional materials such as diagrams, pictures, graphs and flow charts are very essential in the teaching and learning process and more so to a learner with hearing impairments as they reduce language and reading demands. This is because visual methods of teaching and learning create a more lasting experience and relate most readily to other sensory experiences (Sumner, 1985). They make the learning become very interesting even to dull and hyperactive students. A further clarification is made by a Chinese saying, "If I hear I forget, if I see I remember, if I do I know" (Harrison, 1983). By seeing over and over again, the brain may be able to recall what has been learnt. Some of the concepts become more visible and self-explanatory from the

52 www.tucds.edu.np ISSN: 2565-52 I 3 (Print); 2465-839X (Online)


diagrams. It reduces the language demands especially for learners with hearing impairments. From the results of the bivariate analysis, it is found that hearing peers' and societal perception on deafness is positively associated with $\mathrm{HI}$ students' academic performance. The study conducted by Mwanyuma also found negative correlation between negative perception from society with academic performance of deaf learners (Mwanyuma, 2016). Literatures show that presence of $\mathrm{HI}$ parents in family significantly influences the academic achievement of HI students (Harris, 1978). It is described as the children of $\mathrm{HI}$ parents learn sign language from their parents as a first language and they perform better in school. But in our study we found reverse trend. It may be because of parents themselves are not educated and didn't know sign language. So there is no any difference in knowledge of sign language between the student of deaf parent and hearing parents before they go to school and it didn't effect on academic performance.

\section{CONCLUSION}

From the result of the study, it is concluded that the different variables purpose of parent visit to school, teasing by hearing peers, hearing peers' perception, society perception, additional handicapping condition, type of school, level of study, use of sign language by teacher, communication capacity of students, instructional material used by teacher has significant impact on academic performance of $\mathrm{HI}$ students under study. Lack of encouragement and involvement in children' education from parents, negative perception from society and hearing peers on deafness and teasing from hearing peers were found to challenge their academic performance. The study suggests advocacy on societal sensitization on the education of $\mathrm{HI}$ by giving the same status as hearing peers in the society.

Lack of teaching and learning recourses was found to negatively affect the academic performance of $\mathrm{HI}$ students, therefore, the study suggest the government to fully support the special needs education and allocate more recourses to those schools. The study also revealed that the majority of teacher are not very familiar and fluent in using sign language. Thus, the study suggests that the government also fascinates and conducts refresher training to teachers on sign language and thorough pre service and in service training to teachers on how to teach HI students effectively. In this study it is found that only $52 \%$ students got opportunity to learn with specific subject teacher and $\mathbf{8 8 \%}$ teachers couldn't cover all the course content in one academic year, most of them $97 \%$ mentioned that the curriculum is not suitable for $\mathrm{HI}$ students which may be the reason of poor performance of $\mathrm{HI}$ students. So that the study suggests to curriculum development center to revise and simplify the curriculum to make it suitable for HI students. Teachers should be provided with more teaching strategies, flexibility to adapt content and provide classroom accommodations for HI students.

\section{CONFLICT OF INTEREST}

The authors declared that there is no conflict of interest. 


\section{ACKNOWLEDGEMENTS}

Authors would like to acknowledge all those who provided support to this work. Authors would also like to express sincere gratitude to all faculty members of Central Department of Statistics and unknown reviewers for their valuable comments to improve this paper. Mr. Lekha Nath Khatiwada should also be acknowledged for his support during study period.

\section{REFERENCES}

Government of Nepal. (20I5). Constitution of Nepal. Part 3, article 3 I (4). Retrieved from www.lawcommission.gov.np

Government of Nepal. (2014). Analyzing educational status of children with disability and identifying critical intervention to promote their enrollment, retention and success in school: A study report. (Department of Education) Sanothimi, Bhaktapur: Retrieved from http://www.doe.gov.np/assets/uploads/files/33ff7d70 I d8d7c27a6639e64fed7l lbI.pdf

Government of Nepal. (2017). Flash I report 2073 (2016-20I 7). (Department of Education) Sanothimi, Bhaktapur, Nepal.

Government of Nepal. (2016). Education act (2028 BS) $8^{\text {th }}$ amendment 2073BS, Section 6 (kha).

Harris, R. I. (1978). The relationship of impulse control to parent hearing status, manual communication, and academic achievement in deaf children. American Annals of the Deaf, 52-67.

Harrison, J. (1983). Instructional Strategies for physical Education. USA WM. C. Brown Company Publishers.

Hijazi, S.T. \& Naqvi, S.R. (2006). Factor Affecting Student's Performance: A Case of Private College. Bangladesh e-Journal of Sociology. 3(I).

Holt, J. A. (1993). Stanford Achievement Test-8th edition: Reading comprehension subgroup results. American Annals of the Deaf, 138(2), 172-175. Retrieved from https://muse.jhu.edu/article/38563l/summary

Human Rights Watch. (20II). Futures stolen: Barriers to education for children with disabilities in Nepal. New York.

Marschark, M., Shaver, D.M., Nagle, K.M., \& Newman, L. (2015). Predicting the academic achievement of deaf and hard-of-hearing students from individual, household, communication, and educational factors. Except Child, 8 I (3) 350-369. doi: 10.1 | 77/00|44029|4563700.

McCullagh, P. \& Nelder, J. A. (1989). Generalized Linear Models (2nd ed.). London, Chapman and Hall.

Mwanyuma, R. (2016). Factors influencing the academic achievement of deaf learners in kilifi county, kenya: a case of sahajanand school for the deaf (Unpublished Masters dissertation). University of Nairobi, Kenya.

Nepal Government. (2073 B.S.). Inclusive education policy for disabled people. Kathmandu, Nepal 
Powers, S. (2003). Influences of student and family factors on academic outcomes of mainstream secondary school deaf students. Journal of deaf studies and deaf education, 8(I), 57-78. https://doi.org/10.1093/deafed/8.1.57

Sumner, W. (1985). Visual Methods in Education. England, Basil Blackwell Oxford.

Thapalia, M. P. (2016). A report on disability in Nepal 2016. Australian Himalayan Foundation, Sydney, Australia.

United Nations Educational, Scientific and Cultural Organization. (2015). Education for all 2000 2015: Achievements and challenges. EFA Global Monitoring Report, Paris, France.

World Health Organization. (2017). Deafness and Hearing loss. Retrieved from http://www.who.int/mediacentre/factsheets/fs300/en/

York, Gibson \& Rankin. (2015). Defining and measuring Academic Success. Practical Assessment, Research \& Evaluation, 20 (5).

Reference to this paper should be made as follows:

Rijal, T. D, \& Shrestha, G. (2019). Multinomial logistic regression model to identify the factors associated with academic performance of hearing impaired students of some selected districts of Nepal. Nep. J. Stat., 3, 4I-56. 
